\title{
La masonería en el séptimo arte. Una aproximación al caso español
}

\author{
Freemasonry in the Seventh Art. \\ An approach to the Spanish case
}

\begin{abstract}
Ricardo Serna Galindo
Licenciado en Filosofía y Letras (Historia) y Diplomado en Estudios Avanzados de Literatura Española por la Universidad de Zaragoza (España). Máster en Historia de la Masonería Española, por la UNED. Miembro del CEHME (Centro de Estudios Históricos de la Masonería Española, Universidad de Zaragoza) y escritor. Correo electrónico: ricardoserna54@gmail.com
\end{abstract}

DOI: http://dx.doi.org/10.15517/rehmlac.v8i1.24287

Fecha de recibido: 12 de octubre de 2015 - Fecha de aceptación: 5 de enero de 2016

Palabras claves

Cine, Masonería, películas y series, cine masónico en España

Keywords

Films, Freemasonry, movies and series, Masonic cinema in Spain

\begin{abstract}
Resumen
Hemos abordado la cuestión de si existe o no un cine masónico, y nos hemos centrado luego en el examen de varias películas emblemáticas extranjeras que todos conocemos e incluso hemos podido ver y disfrutar, como por ejemplo El hombre que pudo reinar, dirigida por John Huston. A continuación afrontamos el panorama del cine español en su relación con el hecho masónico, resaltando varios filmes de nacionalidad española en los que aparece este asunto de un modo más o menos claro. Sería el caso, entre otras películas, de Bearn o La sala de las muñecas, con guion y dirección de Jaime Chávarri, o El olivar de Atocha, dirigida por Carlos Serrano. En este último caso, la Francmasonería y sus ritos son protagonistas de interesantes pasajes.
\end{abstract}

\begin{abstract}
We have addressed the question of whether there is a Masonic cinema, and we have then focused on the examination of several renown foreign iconic films that we may even have seen and enjoyed, such as The Man Who Would Be King, directed by John Huston. Then we are facing the panorama of Spanish cinema relationship with Freemasonry, by highlighting several films from Spain in which this matter in a more or less clearly displayed. This is the case, amongst other films, of Bearn o La sala de las muñecas _(Bearn or the Dolls' Room), written and directed by Jaime Chavarri, or El olivar de Atocha, the family saga The Olive Tree of Atocha, directed by Carlos Serrano. In the latter case, Freemasonry and its rituals are cast in interesting passages.
\end{abstract}

\section{El tirón de lo masónico}

Los asuntos relacionados, clara o veladamente, con las logias francmasónicas han tenido y siguen teniendo -al menos en España y otros países europeos y americanos-, un considerable atractivo. En el caso español, este fenómeno se debe sin duda a que, desde el 
19 de mayo de 1979, fecha de legalización del Grande Oriente Español (Masonería Española Simbólica Regular), se desató la curiosidad de ciertos medios de información por el regreso de los masones a la nueva España democrática, retorno que estuvo envuelto en una densa cortina de opacidad que vino a reforzar, curiosamente, el halo de misterio que arrostraba desde antiguo esta polémica asociación iniciática.

A partir de la mítica fecha citada, se desató en las estructuras de la hermandad una sorda y nefanda guerra intestina en la que ciertas obediencias pugnaron por liderar el protagonismo de la Masonería española recuperada. El mundo profano no percibió con nitidez las disputas, y solo a través de la prensa se pudo intuir el surgimiento penoso de logias y de algunos líderes que se hicieron sutilmente visibles.

Fue la prensa, sin duda de ningún género, la que favoreció y respaldó con su trabajo el interés de un determinado sector de la sociedad por la Masonería. Y lo hizo a través de noticias y crónicas de prensa, reportajes y entrevistas, artículos y libros en los que la Orden ha tenido protagonismo. La vuelta de los masones a España tras el régimen del general Franco, y sobre todo el hecho de su legalización, fomentó una reacción progresiva de interés por parte de la opinión pública. La información que se traslucía desde los medios, acrecentó la natural curiosidad del ciudadano de a pie, siempre deseoso de husmear en temas con morbo, y éste lo tenía.

Gracias al empuje de los medios, las infraestructuras masónicas han conocido tres décadas largas de lento crecimiento, en especial cuatro organizaciones: la Gran Logia de España, la Gran Logia Simbólica Española, El Derecho Humano y el Gran Oriente de Francia. Hay que señalar, no obstante, que a fecha de hoy conocemos en España más de veinte obediencias masónicas distintas, algunas de ellas con apenas dos o tres docenas de iniciados.

Es patente que los medios audiovisuales y los sitios de Internet, especialmente, han tenido mucho que decir en ese lento pero indiscutible despertar de las logias en suelo español. Buena parte de las personas que se hallaban dubitativas respecto a su ingreso en la Francmasonería, han sido impelidas a la iniciación tras el visionado de incitantes reportajes televisivos o la lectura de entrevistas de periódicos y revistas en las que la imagen fotográfica ha jugado un papel significativo. La estética de la Masonería resulta de interés en la mente de mucha gente, y de ahí que la fuerza de la ilustración gráfica haya jugado sus bazas sustanciales en este proceso. Mal le hubiese ido a la Masonería española de no ser por la propaganda directa que ha tenido gratuitamente por parte de la prensa.

Sin embargo, resulta curioso comprobar cómo el cine con marchamo español no ha prestado apenas interés por ese paulatino despertar de las logias. En los Estados Unidos de América, en cambio, la historia es completamente distinta en este aspecto. 


\section{No existe un cine masónico}

Esta es una cuestión que no admite dudas: de igual manera que no existe una filosofía, una música, una arquitectura o una literatura propiamente masónicas, tampoco hay un cine masónico ${ }^{1}$. Hay que reconocer que todavía hoy se debate en foros residuales mal informados si hay o no unas determinadas artes o disciplinas que sean netamente masónicas. La cuestión está clara y no se presta a debate serio de ningún tipo: no existe en absoluto un cine masónico. El profesor José Antonio Ferrer Benimeli escribe en este sentido que "así como la masonería no tiene, ni puede tener religión propia, ni filosofía, ni doctrina política, sociológica, económica o científica propias, ni una música o arquitectura propias, de igual modo no tiene, por supuesto, una específica y vinculante poética o narrativa"2. La Masonería se sirve de unos determinados elementos culturales que le resultan afines para implementar sus necesidades estéticas y de contenidos. Es una tendencia natural que llevan a cabo, de una forma u otra, casi todas las organizaciones y colectivos.

Comprobamos que literatura y cine son dos tipos de expresión artística que tienen lazos de conexión cercanos y especiales. En el campo de la literatura, hallamos autores que han escrito obras en las que se nota una clara inspiración masónica. Lo mismo sucede con algunos guionistas de cine. En sus obras salen a colación a veces -las menos- los valores que predicaba la histórica Francmasonería tradicional, como la fraternidad, la filantropía, el auxilio mutuo, la libertad de conciencia o la compasión humana. A decir verdad, lo que más abunda entre guionistas de cine no son precisamente los argumentos de fondo en los que se habla de principios, sino las imágenes de la más popular simbología masónica.

Resulta complicado resumir las líneas de influencia rigurosamente masónicas sumidas en obras literarias o en guiones de cine, dada la universalidad de los valores aludidos. La presencia de esos rasgos o la aparición de simbología masónica, poco o nada tiene que ver con el hecho de que el autor del libro o del guion sea o no un iniciado masón. Son muchos los prosistas que han dado su nombre a la Masonería; en cambio, guionistas de cine hay menos. Y en cualquier caso, abundan más fuera de España que en nuestro país, dado que las circunstancias históricas de los siglos XIX y XX marcaron el territorio español como zona resbaladiza para el desarrollo de ciertas proposiciones y conductas.

El soplo de la Francmasonería lo hallamos en microcosmos tan dispares como el de las ciencias, la filosofía, la política, el periodismo, la literatura y hasta el cómic. En la creación cinematográfica también, aunque como decimos habrá que buscarlo mejor en otros

\footnotetext{
${ }^{1}$ Ricardo Serna Galindo, "Masonería y literatura, dos ámbitos en confluencia”, Revista La Página 77, no. 1 (2009): 27-45.

${ }^{2}$ José Antonio Ferrer Benimeli, "Prólogo" a Masonería y Literatura. La Masonería en la novela emblemática de Luis Coloma de Ricardo Serna Galindo (Madrid: Fundación Universitaria Española FUE, 1998), 11.
} 
países alejados del caso español. Reiteramos que no existe un cine masónico, pero vemos una literatura cinematográfica con ciertas influencias masónicas en la que se puede reconocer la presencia de ese hálito particular.

En el mundo del espectáculo cinematográfico hay figuras irrepetibles que fueron iniciados en las logias, como el famoso director Cecil B. de Mille, iniciado en la R.L. Prince of Orange $n^{\circ} 16$, de Nueva York, y actores de la talla de Douglas Fairbanks, al que iniciaron en la R.L. Beverly Hills $n^{\circ} 528$ de California; Glenn Ford, miembro de la R.L. Palisades $n^{\circ} 637$ de California; Stan Laurel y Oliver Hardy, iniciado éste en la R.L. Solomon $n^{\circ} 20$ de Jacksonville, Florida; Clark Gable, iniciado en el mismo taller californiano que Fairbanks; Harold Lloyd, quien solicitó la entrada en la R.L. Alexander Hamilton $n^{\circ} 535$ de California; Harpo Marx, afiliado sin duda a la R.L. Algonquin Round Table de Nueva York; John Wayne, que fue Maestro de la R.L. Marion McDaniel $n^{\circ} 56$ en Tucson, Arizona; o Peter Sellers, que fue Maestro en la R.L. Chelsea $n^{\circ} 3098$ de Londres, y que desempeñó el indecible papel del inspector de policía Clouseau en al menos media docena de ocasiones ${ }^{3}$.

Los podríamos citar por docenas. Pero hay que tener en cuenta que, igual que el cine norteamericano es punto y aparte dentro del conjunto del cine mundial, la Masonería estadounidense también lo era y lo sigue siendo si la comparamos con la del viejo continente europeo. Una y otra no tienen casi nada que ver, especialmente en lo tocante a la aceptación social que tienen las logias por parte de la sociedad donde se ubican, y en la proyección del trabajo social que realizan los masones en bien de la comunidad.

\footnotetext{
${ }^{3}$ Ricardo Serna Galindo, "La Masonería en el cine”, en Revista Cultura Masónica, Año VII no 21, abril, Masonica.es (Ediciones del Arte Real), Oviedo (2015): 21.
} 


\section{Imagen 1}

Peter Sellers (1925-1980) en su casa en Belgravia, Londres, 1973 El actor británico fue maestro en la logia Chelsea $\mathrm{n}^{\mathbf{0}} 3098$ de ciudad de Londres

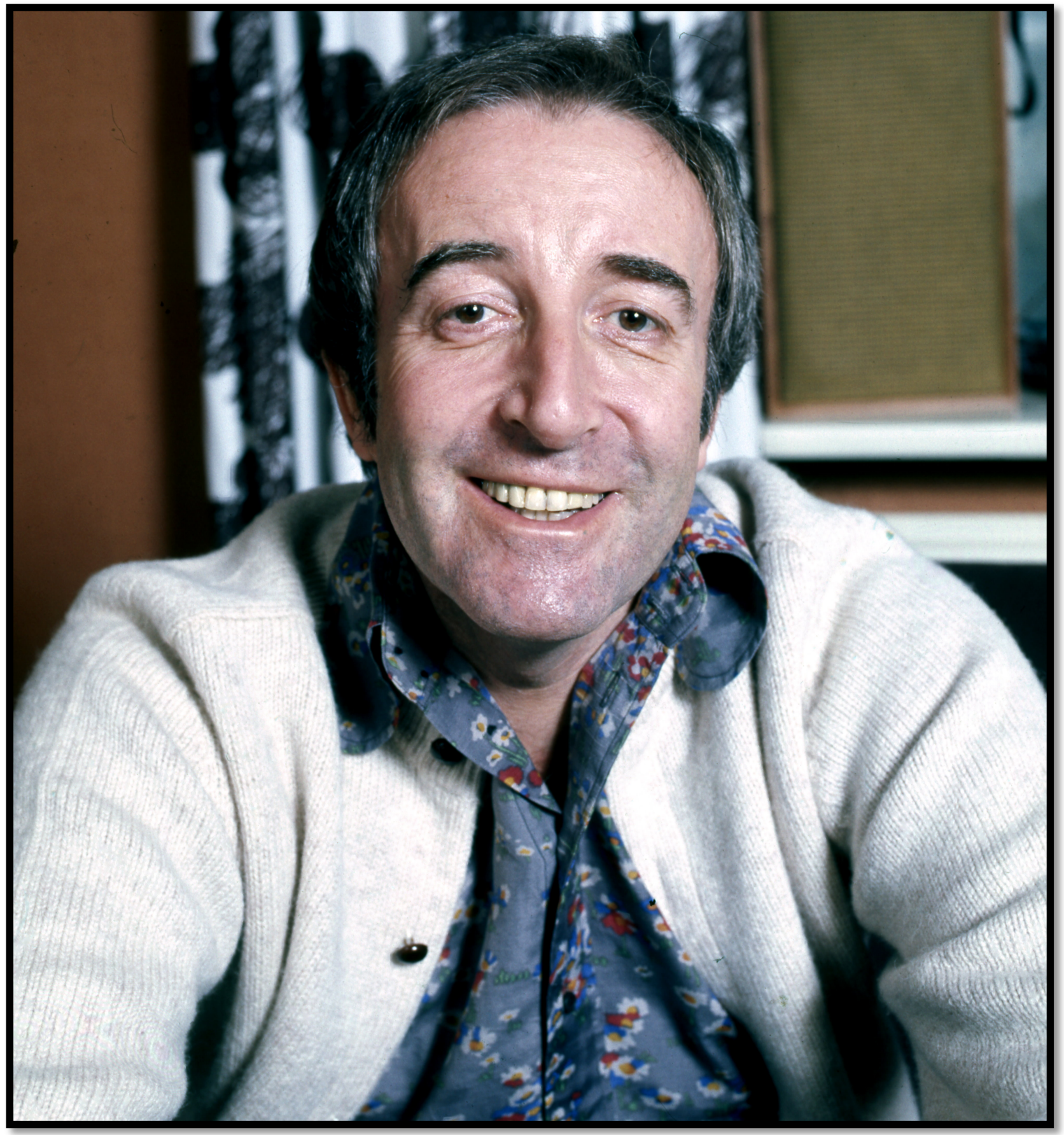

Fuente: Wikimedia.com, "Retrato de Peter Sellers por Allan Warren" (1973 [citado el 3 de enero de 2016]): disponible en https://commons.wikimedia.org/wiki/File:Peter_Sellers_Allan_Warren.jpg 


\section{Algunos filmes inolvidables}

Al hacer memoria para confeccionar un listado mental de las películas con asunto masónico que conocemos, nos damos cuenta enseguida de que no pasan de media docena. Sin embargo, son cientos las que se han filmado a lo largo de los años y no hemos podido ver por una u otra razón, sobre todo porque algunos de esos filmes son antiguos, o porque no se hallan a disposición del público. Para un profano en la materia que quiera conocer la realidad de la presencia masónica en el cine, es obligatorio acudir a fuentes fiables. Una de ellas, inestable por hallarse en una plataforma de Internet, pero interesante por la información que contiene, es el sitio web de la Gran Logia de la Columbia Británica y el Yukon. Si buscamos fuentes más tradicionales, hay que acudir al libro Franc-maçonnerie et le 7ème Art, de Harry Swerts, que es miembro del Gran Oriente de Bélgica. En este caso, el ensayo analiza las complejas conexiones entre las producciones cinematográficas y la realidad masónica 4 .

Gran parte de las películas en las que se alude a la Masonería no son películas sobre la Orden ni sobre su historia o leyenda, sino filmes en los que observamos la simple aparición de símbolos - especialmente la tan manida imagen de la escuadra y el compás con el ojo de Dios en el centro - que a lo sumo identifican a un determinado personaje del film. Podríamos definir estas apariciones esporádicas como guiños masónicos, y ahí se queda todo, en la aparición en pantalla de unos símbolos esotéricos tras los que el espectador medio intuye arcanos o tramas secretas. Es un plus de misterio que algunos guionistas imprimen a los textos para potenciar sus posibilidades.

Lo masónico surge en películas de géneros bien diferentes, incluso en musicales o hasta en comedias. Es el caso de la histórica y divertida Hijos del desierto (1933), protagonizada por Stan Laurel y Oliver Hardy, basada en la pertenencia de sus protagonistas a una sociedad masónica. La cinta se dobló en castellano bajo el peregrino título de Compañeros de juerga. Fue el masón Oliver Hardy, mismamente, quien escribió el guion de este film.

Hay presencia de lo masónico en películas más modernas en las que entran en juego distintas artes escénicas, como en La flauta mágica (1975), de Ingmar Bergman, el genial director sueco de Upsala. Se trata de una adaptación a la gran pantalla de la celebrada y homónima ópera de Mozart. Pero habría que resaltar dos películas que muchos hemos visto y en las que se trasluce igualmente lo masónico: El hombre que pudo reinar (1975), dirigida por John Huston y protagonizada por Sean Connery y Michael Caine, una formidable cinta de aventuras con guion basado en un relato de Rudyard Kipling; y La búsqueda (2004), dirigida por Jon Turteltaub y protagonizada por Nicolas Cage.

\footnotetext{
${ }^{4}$ Harry Swerts, Franc-maçonnerie et le 7ème Art (París: Dervy, 2005).
} 
Podríamos explayarnos trayendo a colación muchas otras películas célebres, como la saga referida a Sherlock Holmes, personaje pergeñado por Arthur Conan Doyle, médico y escritor escocés iniciado en la Masonería. O hablar de las protagonizadas por Jack el destripador, inolvidable personaje del cine policiaco y de misterio. Y no se nos debería olvidar Asesinato por decreto (1979), dirigida por Bob Clark, cuya historia se basa en la supuesta participación de la Masonería londinense en los asesinatos atribuidos al célebre destripador.

Hasta en el cine de animación tenemos ejemplos de películas donde lo masónico se halla presente. El cómic de Hugo Pratt titulado Fábula de Venecia, llevado a la gran pantalla, narra la aventura del marinero maltés Corto, quien toma contacto con la logia Hermes y se ve envuelto sin querer en una aventura llena de acción y copiosa fantasía ${ }^{5}$.

Es preciso apuntar algo que nos parece importante: el hecho de que aparezca la estela de lo masónico en determinadas películas no es precisamente beneficioso para la corporación, ya que vemos un tanto por ciento elevado de casos en los que se hace mofa del ritual masónico, de la indumentaria de los masones o de la misma forma de pensar y actuar de los cofrades. Podríamos confirmar que existe igualmente un cine posicionado frente al fenómeno masónico y contrario a él, lo mismo que pasa en el mundo del libro impreso. Nos viene a la memoria el filme Fuerzas ocultas (1943), realizado bajo el régimen francés de Vichy (1940-1944), una obra de sumo interés en este tipo de filmografía. La dirigió el periodista y cineasta galo Jean Mamy, conocido por el seudónimo de Paul Riche. El guionista del filme fue el escritor Jean Marquès-Rivière, que trabajó para Nova Films. Estuvo protagonizada por el actor Maurice Remy. A pesar de lo sugestivo de esta cinta, de la que podríamos escribir con holgura, nos limitamos a esbozar sus rasgos principales, ya que nos interesa centrarnos substancialmente en el caso del cine español.

El argumento del film no merecería la pena destacarse de no ser porque, a lo largo de la película se capta, con exquisitos detalles de exactitud, un rito de iniciación en el interior de una logia. Hasta esa fecha, que sepamos, esto había sido completamente inédito en el cine. La película aporta veracidad documental y ofrece una imagen muy singular, aunque algo escorada, de la Masonería de aquel momento histórico tan complicado para Francia y los franceses.

El 5 de mayo de 2012, la logia Mozart auspició una proyección de la versión íntegra subtitulada en castellano de esta película histórica. Se llevó a cabo en el salón de actos del Ateneo de Madrid. También existe una versión subtitulada en idioma italiano. La logia Wolfgang Amadeus Mozart se constituyó en Madrid en enero de 2004, auspiciada por el Gran Oriente de Francia (GOdF).

\footnotetext{
${ }^{5}$ Ricardo Serna Galindo, "Masones en el cómic. La Masonería y Corto Maltés, de Hugo Pratt", en Ricardo Serna, Estudios masónicos. Cinco ensayos en torno a la Francmasonería (Santa Cruz de Tenerife, Ediciones Idea, 2008), pp. 159-214.
} 


\section{Imagen 2}

Cartel comercial de la película Fuerzas ocultas, dirigida por Paul Riche, un film que desvela el rito de iniciación de manera fidedigna, como antes no había sido mostrado.

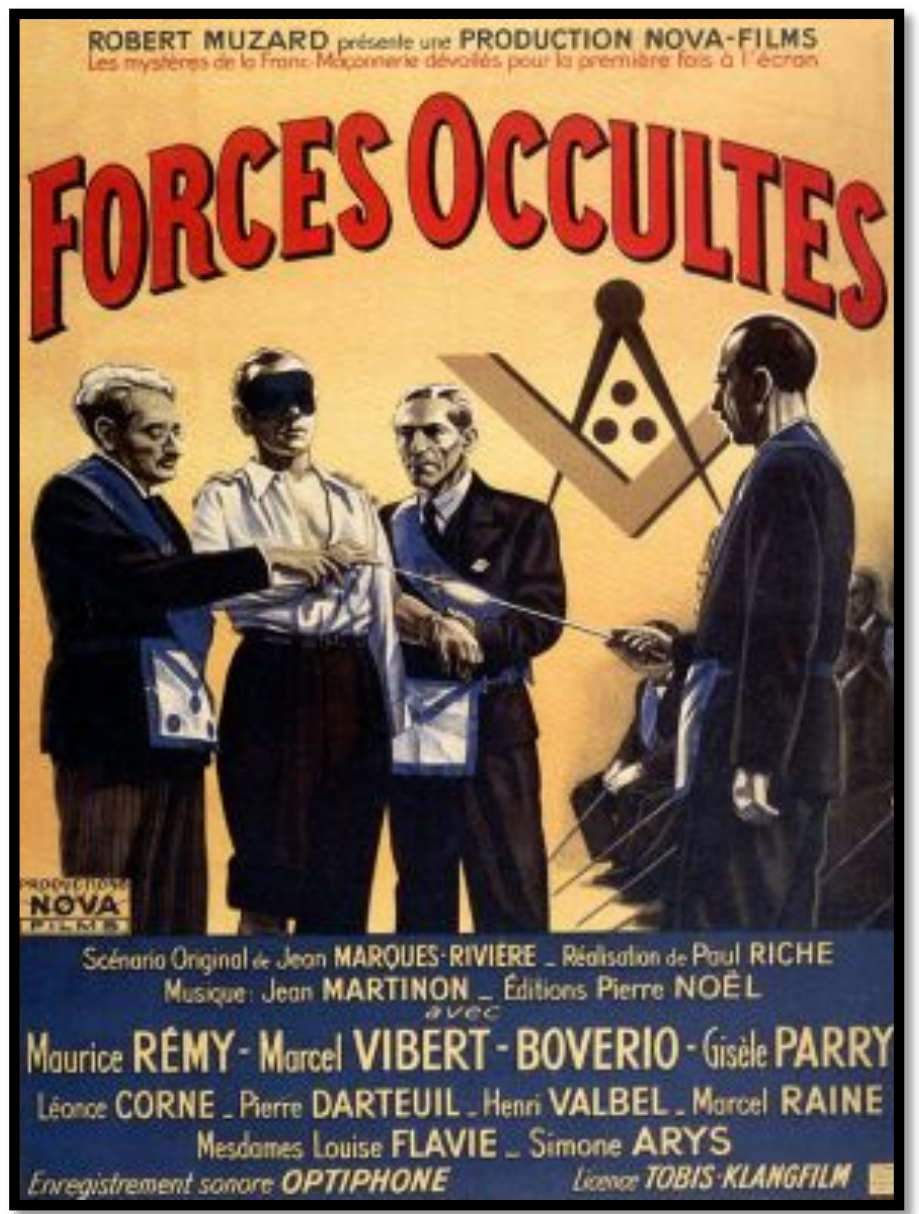

Fuente: Movieposterdb.com, "Poster de Forces occultes" (1943 [citado el 10 de enero de 2016]): disponible en

http://www.movieposterdb.com/posters/08 01/1943/189529/1 189529 25f4be7e.jpg

\section{El simbolismo masónico en el cine español}

Traemos aquí varios ejemplos de cómo la Francmasonería se hace presente en el cine español. Son bien escasos los guionistas que se han embarcado en el tratamiento del asunto, posiblemente porque la ignorancia de la realidad histórica de esta orden ha sido y sigue siendo muy notable.

La película Raza, dirigida por Sáenz de Heredia en 1942, no tiene un argumento masónico como tal, pero contaremos a vuela pluma que narra la peripecia vital de cuatro hermanos -Isabel, Pedro, José y Jaime-, hijos del capitán de navío Pedro Churruca, quien emulando a un ilustre antepasado muere en Cuba al principio de la cinta mientras se halla 
en misión patriótica contra la armada de los Estados Unidos. Su muerte se achaca a la Masonería, organización atea y republicana que domina la política española desde las sombras y que se supone ha dejado en la estacada a las últimas tropas que defienden las colonias a sangre y fuego. El guion fue escrito por José Luis Sáenz de Heredia, quien se basó en una novela homónima firmada por Jaime de Andrade, seudónimo de Francisco Franco, que fue publicada en 1942 por la editorial Numancia. Esta película se dedica sobre todo a ensalzar el espíritu nacional del bando vencedor en la guerra civil, y no es razonable considerar masónicos ni antimasónicos sus argumentos en ninguna de sus partes. De ahí que no la incluyamos en este breve ensayo.

\section{El ángel exterminador (1962)}

Dirigida por Luis Buñuel, es un filme mexicano surrealista que consideramos raro, estrafalario y de escaso interés en lo que al asunto masónico se refiere. Aún así dejaremos constancia de que en la cinta observamos un par de guiños masónicos: uno de los protagonistas resulta ser miembro de la logia Amanecer $n^{\circ} 21$ del Gran Oriente de México; y en otra escena, dos personajes se estrechan la mano a la vez que se transmiten la palabra de paso del segundo grado. La presencia de estos guiños, enmarcados sin pies ni cabeza en un filme surreal que no trata en absoluto de la Masonería ni de su sombra, solo responden a la voluntad de Buñuel por agradar y empatizar con miembros influyentes del gobierno mexicano, dominado entonces por el muy poderoso Partido Revolucionario Institucional (PRI), bien nutrido de masones. La película se rodó en México con presupuestos ajustados. Luis Buñuel no fue nunca masón, y no estuvo tampoco interesado jamás por ahondar en los ritos y principios de la orden, ni en lo personal ni en lo cinematográfico.

\section{Bearn o La sala de las muñecas (1982)}

Fue dirigida por Jaime Chávarri y es una adaptación argumental de una novela del escritor mallorquín Llorenç Villalonga y Pons (Palma de Mallorca, 1897-1980), hermano del también escritor Miguel Villalonga. Escribió tanto en catalán como en castellano, y está considerado una de las figuras más significativas de la literatura catalana del pasado siglo. La novela se publicó en 1956, aunque en 1961 se volvió a editar en lengua catalana ${ }^{6}$.

Esta obra se considera una gran novela, quizá una de las más interesantes de la literatura en catalán del siglo pasado. A pesar de su incuestionable interés, el relato no fue bien recibido por nadie, ni por la crítica ni por el público. El texto había optado al premio Nadal y también al premio Ciudad de Barcelona, pero no ganó ninguno, lo que defraudó bastante las expectativas puestas en ella por el escritor isleño. Una vez que la novela

\footnotetext{
${ }^{6}$ En 1956 apareció la primera edición en castellano, con una tirada de mil ejemplares. Salió acompañada de un texto del insigne Camilo Cela titulado "Prólogo parabólico", que incomodó bastante al autor mallorquín porque en él se especula sobre su condición de judío.
} 
empezó a rodar en catalán, fue recompensada con el Premio de la Crítica en 1963, y en una encuesta de Serra d' Or realizada en 1964 se la citaba como la segunda mejor novela de la literatura catalana después de La plaza del Diamante, de Mercè Rodoreda. Actualmente, Bearn o La sala de las muñecas está catalogada como uno de los clásicos catalanes del siglo XX, y ha sido traducida a numerosos idiomas.

\section{Imagen 3}

Llorenç Villalonga y Pons (1897-1980), autor de la novela Bearn o La sala de las muñecas

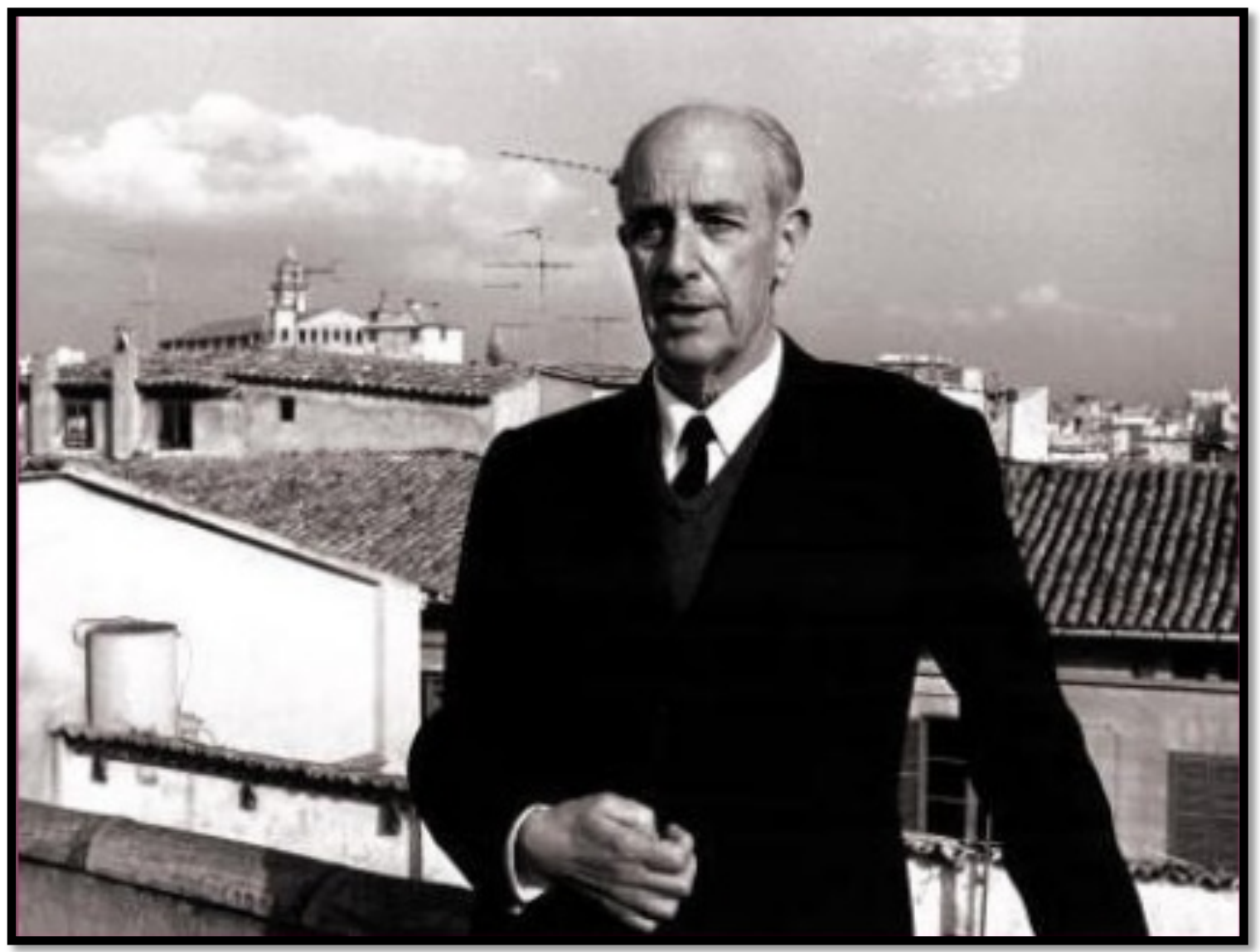

Fuente: Literatura catalana contemporània, "Llorenç Villalonga: escriptors anticatalans de Mallorca" (2011 [citado el 2 de febrero de 2016]): disponible en http://turmeda.balearweb.net/post/104646

Vayamos con una síntesis del argumento. El narrador de la novela, Joan Mayol, a la sazón capellán de la casa y posible hijo natural del señor de Bearn, escribe a Miquel Gelabert, un antiguo compañero suyo de seminario que ostenta el cargo de secretario del cardenal primado. La carta está fechada en Bearn en 1890, transcurridos dos meses desde la muerte de los señores. Mayol desea someter a la consideración de sus superiores eclesiásticos si debe o no obedecer la última voluntad del difunto señor de Bearn, que 
consiste en la publicación de sus memorias. Mayol adjunta para ello un manuscrito (el grueso de la novela, en realidad), donde relata su vida en Bearn y la fascinación que sintió por la personalidad de don Antonio. En los capítulos agrupados en el epígrafe "Bajo el influjo de Faust" se cuenta, en veinte capítulos, que igual que el personaje de Goethe vende su alma al diablo para conseguir la perseguida eterna juventud, el protagonista de Bearn la vende también cuando decide abandonar a su esposa y huir a París con su sobrina Xima, de dieciocho tiernos años, para asistir precisamente al estreno de la ópera Fausto, de Gounod, el 19 de marzo de 1859. Después de medio año en danza por esos mundos, don Antonio regresa de París, mientras que Xima decide quedarse allí alternando en la corte con las figuras más descollantes y vividoras del Imperio. A la vuelta de don Antonio a Bearn, su esposa se separa de él. En "La paz reina en Bearn", se narra la vida de los señores en sus posesiones, interrumpida por un viaje a París y Roma. En esta etapa, don Toni se dedica a escribir sus memorias. Al final regresa Xima, pobre y mayor, y los tres personajes mueren en extrañas circunstancias. En el epílogo, Joan Mayol es visitado por unos investigadores de la Masonería que pretenden conocer los secretos que esconde la llamada 'sala de las muñecas', habitación siempre cerrada a cal y canto y que debe su nombre a la afición de un antepasado de los Bearn por la que había sido expulsado del ejército. Mayol quema el contenido de la habitación para preservar indemne la memoria del señor de Bearn.

El relato literario fue adaptado para la televisión en el año 1976. Y posteriormente, en 1982, el archiconocido director madrileño Jaime Chávarri de la Mora estrenó una adaptación cinematográfica de la novela, muy conseguida por cierto. La película fue protagonizada por el magnífico e inolvidable actor Fernando Rey y otros compañeros de profesión de la talla de Alfredo Mayo, Ángela Molina, Amparo Soler Leal e Imanol Arias.

\section{El olivar de Atocha (1989)}

Dirigida por Carlos Serrano, y concebida primero como una serie televisiva, consta de veintiséis capítulos. Fue emitida por primera vez en Televisión Española el año 1989. Su argumento narra la saga de una familia afincada en Madrid entre los primeros años de 1900 y el comienzo de la guerra civil de 1936. El personaje femenino principal es Manolita, que llega desde su Galicia natal a la fábrica de muebles construida en lo que antes fue el olivar de Atocha, en Madrid, y cuya portera es Vicenta. Allí conoce al que se convertirá en su marido, Antonio Malmedina. Juntos experimentarán en carne propia los acontecimientos de la época.

Está basada en una trilogía de la escritora Dolores Salvador Maldonado, que usaba los seudónimos de Salvador Maldonado y Lola Salvador, éste último de manera más habitual. La escritora colaboró además en la conformación del guion de la serie. Las novelas que forman la trilogía se titulan: La sonrisa de Madrid, Mamaíta y Papantonio, y El mar de la leonera, publicadas por la editorial Plaza y Janés en 1988 y 1989. De la guionista y escritora diremos que tuvo una formación autodidacta y que, entre los años 
1962 y 1970, colaboró en labores técnicas y artísticas en los mundillos periodísticos de la prensa escrita, la radio, el cine y la televisión ${ }^{7}$. Su trabajo se enfocó principalmente hacia la creación de novelas y de guiones para cine. Fue la fundadora de la productora «Brothers \& Sisters», produjo la película Salvajes, de Carlos Molinero, y fue premiada con un Goya al mejor guion adaptado. Ha escrito numerosos guiones radiofónicos para programas como Con los ojos cerrados (1972-1973), un diario de divulgación literaria. Para el teatro ha adaptado clásicos como La gata sobre el tejado de zinc, de Tennessee Williams, en 1984, y Espectros, de Henrik Ibsen, estrenada en 1993.

\section{Imagen 4}

La escritora Lola Salvador Maldonado (1938-), guionista de El olivar de Atocha

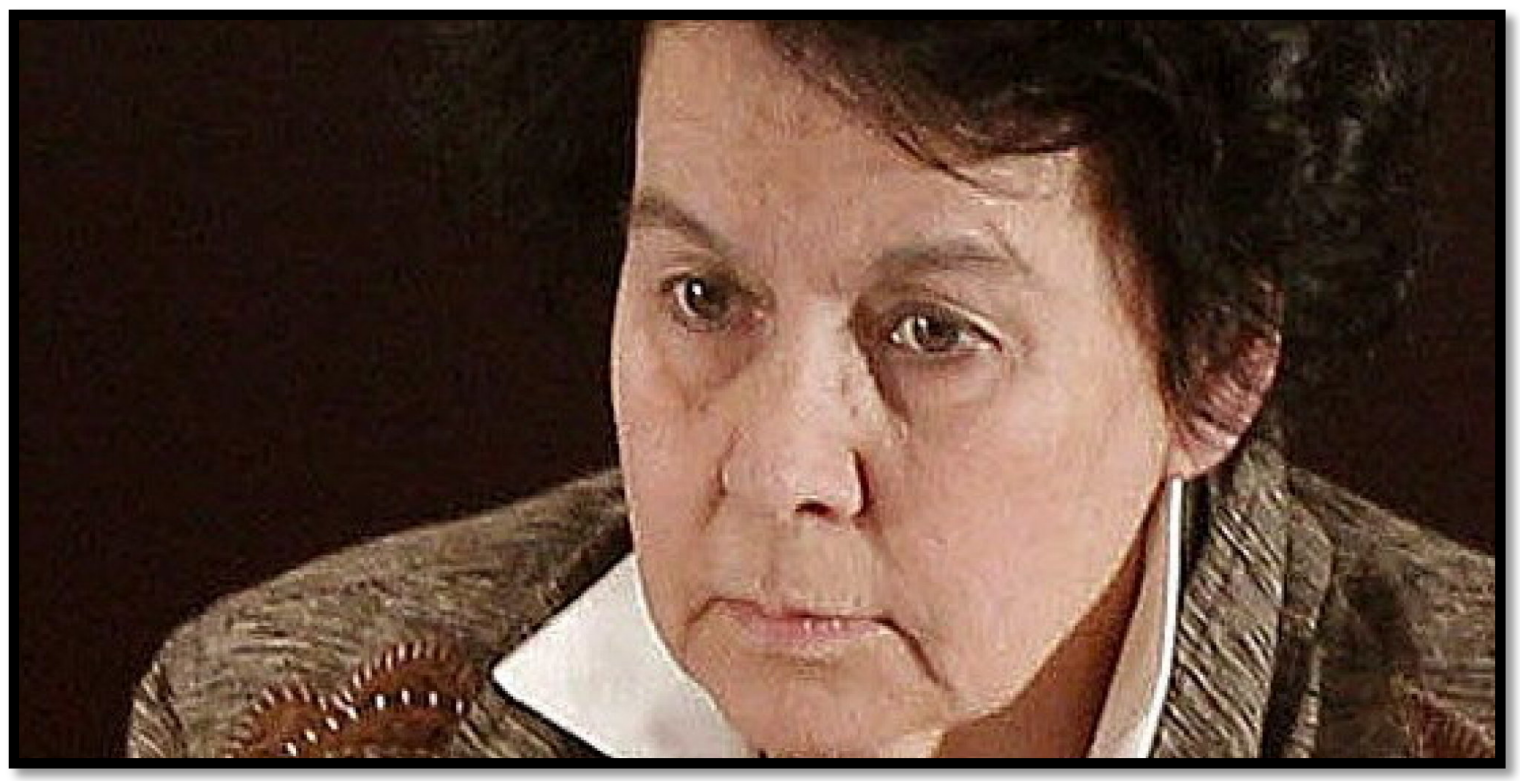

Fuente: El Huffington Post, "Lola Salvador, Premio Nacional de Cinematografía 2014" (2011 [citado el 2 de febrero de 2016]): disponible en http://www.huffingtonpost.es/2014/07/15/lola-salvador-premio-nacionalcine n 5587553.html

Como novelista publicó en 1979 la titulada El crimen de cuenca, basada en su guion para la película homónima de Pilar Miró, y La sonrisa de Madrid (1988), junto con Mamaita y Papantonio y El mar de la leonera (1989), que como queda dicho forman la trilogía El olivar de Atocha. Entre sus guiones para el cine destacan también los realizados para las películas del director Jaime Chávarri Bearn o La sala de las muñecas (1982), Las bicicletas son para el verano (1984) — que adapta la obra teatral homónima de Fernando Fernán Gómez - y Tierno verano de lujurias y azoteas (1993). En 2011 se le otorgó la

\footnotetext{
7 Susana Díaz, Modos de mostrar. Encuentros con Lola Salvador, Getafe, Grupo de Investigación «Televisión-Cine: memoria, representación e industria» (Madrid: Universidad Carlos III, 2012).
} 
Medalla de Oro al Mérito en las Bellas Artes. Y en julio de 2014 le fue concedido el Premio Nacional de Cinematografía.

\section{Masones. Los hijos de la viuda (2009)}

En este caso, no se puede hablar de una película al uso, sino de un documental dramatizado con guion y dirección de Santiago Lapeira y fotografía de Ernest E. Sala.

Los principales intérpretes de la película fueron Elena Cruz, Mafer Blanco, Kepa Atxa, Marisa Duaso y Francesc Bosch. Otras películas de este mismo director catalán son Asalto al banco central (1982), Rescate (2007), y El secreto de los 24 escalones (2011).

Anotando lo esencial de los contenidos, señalaremos que cuando Marta, una joven catedrática, descubre que su padre había dado su nombre a la Masonería, ella siente la necesidad de embarcarse en un viaje especial para conocer los misterios masónicos escondidos en ciudades como Estambul, París, Roma, Madrid, Bilbao y Barcelona. Su periplo le llevará a comprender la relación de Gaudí con los masones, la vida interna de los talleres, los ritos que practican los iniciados y la supervivencia de estas sociedades secretas en la actualidad. Se trata de un documental de ficción que desvela al espectador lugares ligados de alguna forma a la Francmasonería. Con esta película se pretende quitar hierro a la versión conspirativa que, de esta discutida asociación, han propagado algunos libros y películas precedentes. Podríamos definirla como una película amable con la sociedad francmasónica.

\section{Silencio en la nieve (2012)}

La novela que originó esta adaptación cinematográfica lleva por título El tiempo de los emperadores extraños, de Ignacio del Valle, quien elige la División Azul y sus lances bélicos como telón de fondo de los argumentos de la obra. Mezcla en ellos un turbio asunto de crímenes rituales, homosexualidad y tensiones entre facciones fascistas. La película, del año 2012, nos parece interesante en lo que atañe a la documentación y ambientación, a pesar de permitirse alguna que otra licencia a lo largo del guion.

El joven y esplendente escritor nació en Oviedo en 1971, aunque vive en Madrid. Ha publicado ocho libros: un volumen de relatos, Caminando sobre las aguas (2013) y siete novelas, entre ellas las tituladas Los demonios de Berlín, El tiempo de los emperadores extraños, El arte de matar dragones, y De donde vienen las olas. Sus libros se han traducido a varios idiomas. Es columnista en el diario El Comercio de Gijón, y colaborador de radio $^{8}$.

\footnotetext{
${ }^{8}$ Ignacio del Valle, Caminando sobre las aguas (Madrid: Páginas de Espuma, 2013); Busca mi rostro (Barcelona: Plaza y Janés, 2012); Los demonios de Berlín (Madrid: Alfaguara, 2009); El tiempo de los emperadores extraños (Madrid: Alfaguara, 2006); El arte de matar dragones (Madrid: Algaida, 2003); Cómo el amor no transformó el mundo (Barcelona: Espasa, 2005); El abrazo del boxeador (Oviedo: KRK Ediciones, 2001); y De donde vienen las olas (Alicante: Aguaclara Ediciones, 1999).
} 
Imagen 5

Cartel comercial de la película Silencio en la nieve

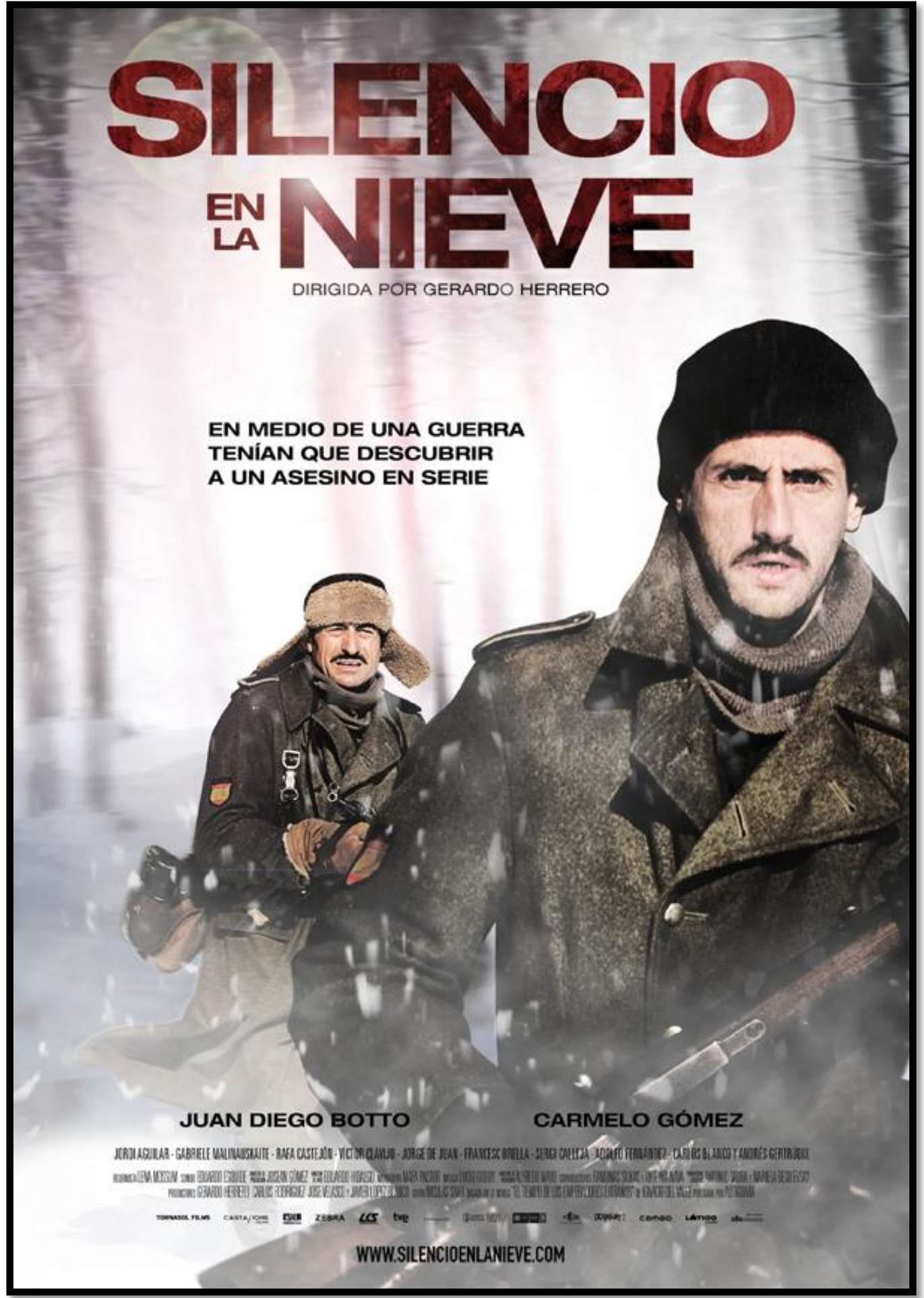

Fuente: Filmaffinity.com, "Silencio en la nieve" (2011 [citado el 2 de febrero de 2016]): disponible en http://www.filmaffinity.com/es/film255705.html 
El filme está dirigido por Gerardo Herrero. La cinta tiene un ritmo premioso y parece buscar la senda del best-seller, al tiempo que denuncia los horrores de la guerra. Entre los actores vemos a Juan Diego Botto, Carmelo Gómez y Víctor Clavijo.

Gerardo Herrero es un director, guionista y productor nacido en Madrid en 1953. Su trayectoria en el mundo del cine es dilatada y notoria. Licenciado en Derecho por la Universidad Complutense de Madrid, fundó en 1987 la productora Tornasol Films, con la que ha producido medio centenar de películas. Su debut como director fue en la cinta titulada Al acecho (1987). También ha dirigido Malena es un nombre de tango (1996), basada en un relato novelesco de Almudena Grandes, Territorio comanche (1997), Las razones de mis amigos (2000), El misterio Galíndez (2003), Una mujer invisible (2007), Silencio en la nieve (2012), y La playa de los ahogados (2014). Entre los años 1993 y 1994, presidió la Academia Española de Artes y Ciencias Cinematográficas y es miembro fundador de la Escuela de Cine de Madrid.

El argumento de la película nos sitúa en el frente ruso durante el invierno de 1943. Un batallón de la División Azul se topa con un soldado español muerto en extrañas circunstancias. El cuerpo presenta una hendidura que le atraviesa el cuello, y en el hombro lleva una misteriosa inscripción grabada a cuchillo: "Mira que te mira Dios". Al soldado Arturo Andrade, exinspector de la policía, se le encarga la investigación del caso, en la que se relaciona el asesinato con la sociedad secreta de la Masonería.

\section{Breves conclusiones}

No vamos a negar que llama la atención la enorme cantidad de películas en las que, sin más ni más, aparecen los símbolos más populares de la Francmasonería; ocurre sobre todo en el cine americano, pero ya vamos viendo películas europeas con esa misma tendencia. Es como si el hecho de embutirlos en el guion aportase un plus de misterio o aventura al argumento de la película donde se encajan. Son muy pocas, por el contrario, las cintas que tratan de verdad alguno de los aspectos de la sociedad.

A la vista de lo dicho, nos podemos preguntar de qué manera aparece reflejada la Masonería en los guiones de cine y en los desarrollos cinematográficos. Y en este sentido, observamos que las logias aparecen asociadas fundamentalmente a tres asuntos: la aventura misteriosa, el crimen oscuro y la conspiración en la sombra. De lo primero, nada que añadir; de lo demás anotar que estos argumentos, sin ser puramente antimasónicos, no benefician en nada la imagen corporativa de la Masonería. Ya sabemos que el cine es solo cine y que la ficción es la dueña y señora de guiones y producciones, pero habría que preguntarse el porqué de la relación argumental -exitosa, por cierto- entre lo criminal y la orden, que siempre se perfila con rasgos de complot y secretismo. 
Es obligado resaltar igualmente la exigua repercusión que los argumentos masónicos han tenido hasta la fecha en el panorama del cine español. Nos parece un hecho significativo. Es obvio que productores, guionistas y directores no han mostrado en España el menor interés por abordar de alguna manera el tema de las logias. Ni ha existido ese interés, ni se le espera.

\section{Bibliografía}

Díaz, Susana. Modos de mostrar. Encuentros con Lola Salvador, Getafe, Grupo de Investigación "Televisión-Cine: memoria, representación e industria”. Madrid: Universidad Carlos III, 2012.

Ferrer Benimeli, José Antonio. "Prólogo" a Masonería y Literatura. La Masonería en la novela emblemática de Luis Coloma de Ricardo Serna Galindo. Madrid, Fundación Universitaria Española FUE, 1998.

Serna Galindo, Ricardo. "Masones en el cómic. La Masonería y Corto Maltés, de Hugo Pratt". En Estudios masónicos. Cinco ensayos en torno a la Francmasonería. Editado por Ricardo Serna Galindo. Santa Cruz de Tenerife: Ediciones Idea, 2008.

Serna Galindo, Ricardo. "Masonería y literatura, dos ámbitos en confluencia”. Revista La Página 77, no. 1 (2009): 27-45.

Serna Galindo, Ricardo. "La Masonería en el cine”. Revista Cultura Masónica VII, no. 21 (2015): 21.

Swerts, Harry. Franc-maçonnerie et le 7ème Art. París: Dervy, 2005.

Valle, Ignacio del. El tiempo de los emperadores extraños. Madrid: Alfaguara, 2006. 